\title{
Severe hyperprolactinaemia is associated with decreased insulin binding in vitro and insulin resistance in vivo
}

\author{
G. Schernthaner, R. Prager, C. Punzengruber and A. Luger \\ Department of Medicine II, Division of Metabolism and Endocrinology, University of Vienna and Ludwig Botzmann-Institute \\ for Clinical Endocrinology, Vienna, Austria
}

\begin{abstract}
Summary. We studied insulin receptor binding and carbohydrate metabolism in 10 patients with severe hyperprolactinaemia and compared the findings with those obtained in 20 healthy control subjects. Insulin binding to monocytes and erythrocytes was significantly decreased in the patients with an excess of prolactin. Scatchard analysis of binding data indicated that a decrease in the number of receptors rather than in receptor affinity seems to be the prevailing cause of lowered binding in hyperprolactinaemic patients. Furthermore, patients with severe hyperprolactinaemia demonstrated significantly elevated blood glucose levels following oral or intravenous glucose load despite having significantly increased
\end{abstract}

insulin levels after glucose administration. The infusion of insulin induced a delayed hypoglycaemic effect and a decreased inhibition of endogenous insulin secretion, as indicated by the suppression of C-peptide in the hyperprolactinaemic patients. The present data indicate that severe hyperprolactinaemia is associated with an insulin-resistant state, which seems to be caused, at least in part, by a down-regulation of insulin receptors.

Key words: Hyperprolactinaemia - insulin receptor binding monocytes - erythrocytes - insulin resistance.
Infusion experiments in animals [1,2] and in man [3] have shown that prolactin may have a diabetogenic action. Various clinical studies in hyperprolactinaemic patients [4-6] with or without pituitary tumours have revealed hyperinsulinaemia. In these studies, impaired glucose tolerance was noted in some but not all patients. By contrast, other investigators could not demonstrate a diabetogenic effect of prolactin either in man [7-9] or in animals [10, 11]. Furthermore, the underlying mechanisms involved in prolactin-induced changes in insulin release and glucose homeostasis are unknown. Therefore, to clarify the reasons for these discrepant findings and to evaluate further the rate of carbohydrate metabolism in hyperprolactinaemia, insulin receptor binding to monocytes and erythrocytes was studied in carefully selected hyperprolactinaemic patients, not presenting with any other pituitary dysfunctions and well defined for glucose tolerance and insulin secretion.

\section{Patients and methods}

\section{Patients}

Ten patients (five females, five males; mean age $37 \pm 3.5$ years) with prolactinomas were studied. The clinical data and laboratory parameters of all patients and control subjects are summarized in Table 1. Seven of the patients presented with pituitary tumours diagnosed by
X-ray tomography of the sella turcica and/or computerized axial tomography. In three patients (nos. 4, 5 and 10) in whom there was no radiological evidence of a macroprolactinoma, it was assumed that microadenomas were present, since none of the factors usually associated with persistent hyperprolactinaemia could be identified. The patients were selected carefully; they all had normal (or near normal) body weight (Table 1) and normal pituitary functions, except for hyperprolactinaemia. None of the patients had any illnesses other than hyperprolactinaemia, and none was on medication at the time of the study. Secretion of growth hormone and cortisol was normal, as measured by responses to insulin-induced hypoglycaemia. In addition, plasma concentrations of gonadotropins, total testosterone, thyroid hormones and thyrotropin showed no differences between patients and control subjects. Plasma levels of oestradiol were significantly lower in the hyperprolactinaemic patients compared with the control subjects (Table 1) and plasma concentrations of dehydroepiandrosterone sulphate (DHAS) were significantly higher. None of the patients was overtly diabetic according to World Health Organization criteria [12] and none had a family history of diabetes. The patients were admitted to the Division of Metabolism and Endocrinology and placed on a standard diet of $40 \mathrm{kcal} / \mathrm{kg}$ body weight with $40 \%$ carbohydrate. Informed consent was obtained from all patients before the study and the investigations reported were performed in accordance with the principles of the Declaration of Helsinki.

\section{Control subjects}

The 20 control subjects ( 10 males, 10 females) were recruited from the medical and paramedical staff of our hospital. From 3 days before the study and throughout the study period, their diet was identical to that of the patients. In addition, their physical activity was comparable with that of the patients. The mean age and mean body mass index of the control subjects and the patients were similar (Table 1). 
Table 1. Clinical data and laboratory parameters ${ }^{\mathrm{a}}$ of hyperprolactinaemic patients and control subjects

\begin{tabular}{|c|c|c|c|c|c|c|c|c|}
\hline Subjects & $\begin{array}{l}\text { Age } \\
\text { (years) }\end{array}$ & Sex & $\begin{array}{l}\text { Body mass } \\
\text { index } \\
\left(\mathrm{kg} \div \mathrm{m}^{2}\right)\end{array}$ & $\begin{array}{l}\text { Immunoreactive } \\
\text { prolactin } \\
(\mathrm{nmol} / \mathrm{l})\end{array}$ & $\begin{array}{l}\text { Blood glucose } \\
(\mathrm{mmol} / 1)\end{array}$ & $\begin{array}{l}\text { Immunoreactive } \\
\text { insulin } \\
\text { (pmol/1) }\end{array}$ & $\begin{array}{l}\text { Oestradiol } \\
(\mathrm{pmol} / \mathrm{l})\end{array}$ & $\begin{array}{l}\text { DHAS } \\
(\mu \mathrm{mol} / 1)\end{array}$ \\
\hline 2 & 57 & $\mathbf{F}$ & 25 & 81 & 4.6 & 78 & 198 & 8.6 \\
\hline 3 & 15 & $\mathrm{M}$ & 21 & 22 & 4.0 & 42 & 194 & 10.7 \\
\hline 4 & 43 & M & 23 & 6 & 4.2 & 116 & 101 & 10.5 \\
\hline 5 & 33 & $\mathrm{~F}$ & 26 & 6 & 5.3 & 164 & 240 & 6.5 \\
\hline 8 & 42 & $\mathrm{~F}$ & 26 & 14 & 4.9 & 18 & 312 & 6.8 \\
\hline 9 & 32 & $\mathrm{M}$ & 22 & 209 & 4.5 & 118 & 196 & 11.6 \\
\hline 10 & 37 & $\mathrm{~F}$ & 23 & 14 & 3.3 & 147 & 320 & 8.5 \\
\hline Mean \pm SEM & $36.9 \pm 4.5$ & $5 \mathrm{~F} / 5 \mathrm{M}$ & $23.9 \pm 0.6$ & $50 \pm 2$ & $4.4 \pm 0.2$ & $106 \pm 17$ & $211 \pm 23$ & $8.9 \pm 0.6$ \\
\hline $\begin{array}{l}\text { Control } \\
\text { subjects } \\
(n=20)\end{array}$ & $41.3 \pm 4.3$ & $10 \mathrm{~F} / 10 \mathrm{M}$ & $23.1 \pm 0.5$ & $0.4 \pm 0.1$ & $4.0 \pm 0.07$ & $59 \pm 20$ & $320 \pm 36$ & $5.8 \pm 0.8$ \\
\hline
\end{tabular}

a All hormonal parameters were analysed in patients and control subjects in fasting state

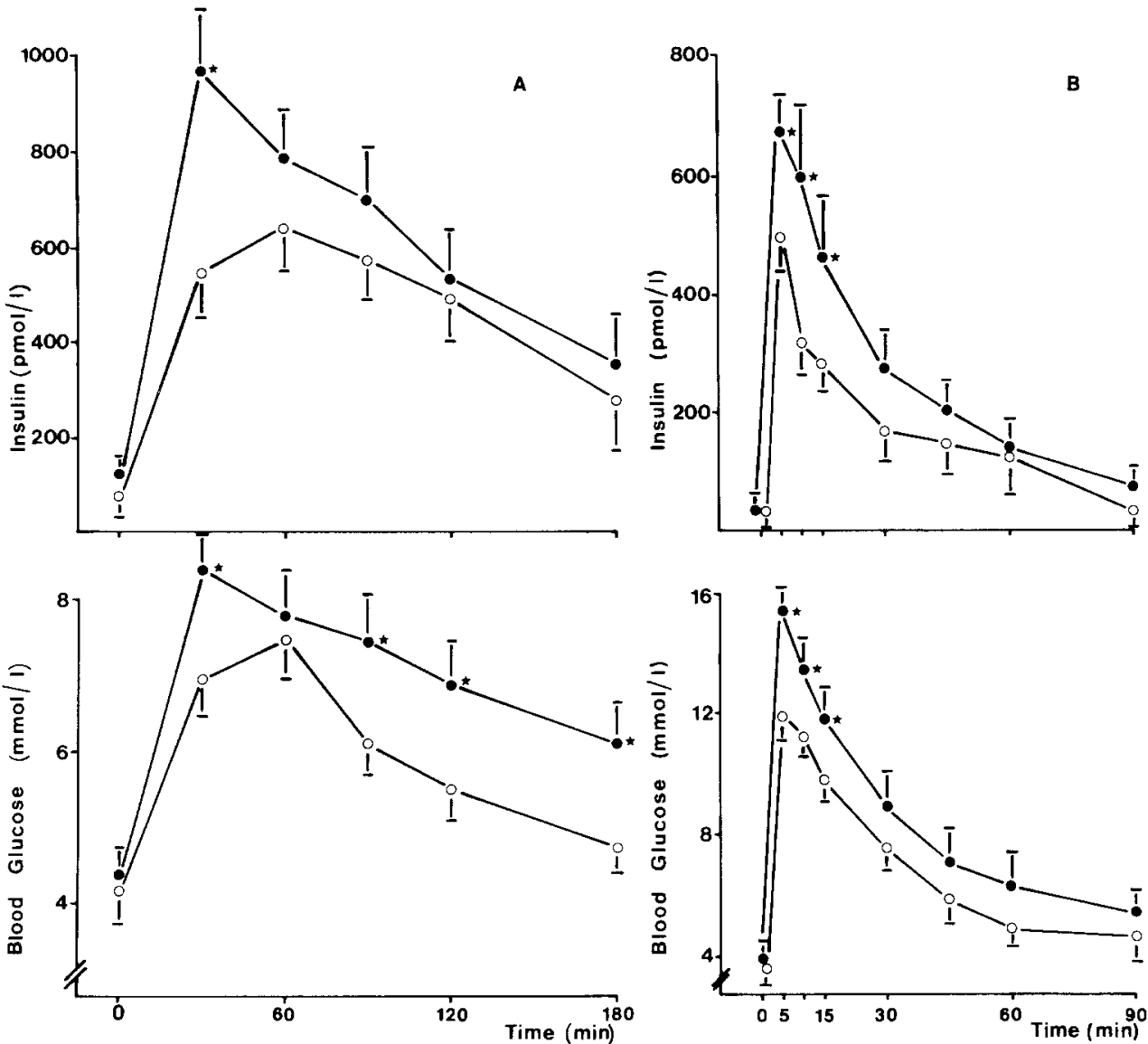

Fig. 1. Plasma insulin and blood glucose levels during oral glucose tolerance test (Fig. 1 A) and intravenous glucose tolerance test (Fig. 1 B) in hyperprolactinaemic patients and controls. hyperprolactinaemic patients $(n=10) ; 0-0$ control subjects $(n=20) ; * p<0.01$

\section{Methods}

Three days after the patients had been admitted to hospital, the insulin receptors on monocytes and erythrocytes were determined. To document the degree of glucose intolerance, insulin secretion and decreased sensitivity to insulin, an oral glucose tolerance test $(100 \mathrm{~g}$ glucose), an intravenous glucose tolerance test $(0.33 \mathrm{~g}$ glucose $/ \mathrm{kg}$ body weight) and an insulin tolerance test ( $0.1 \mathrm{U}$ Actrapid MC Insulin No- vo/ $\mathrm{kg}$ body weight infused over a period of $60 \mathrm{~min}$ ) were performed on all patients and control subjects.

\section{Insulin binding studies}

Studies on insulin binding to monocytes and erythrocytes were carried out in the morning after patients and control subjects had fasted overnight. Blood $(120 \mathrm{ml})$ was drawn into tubes containing EDTA 

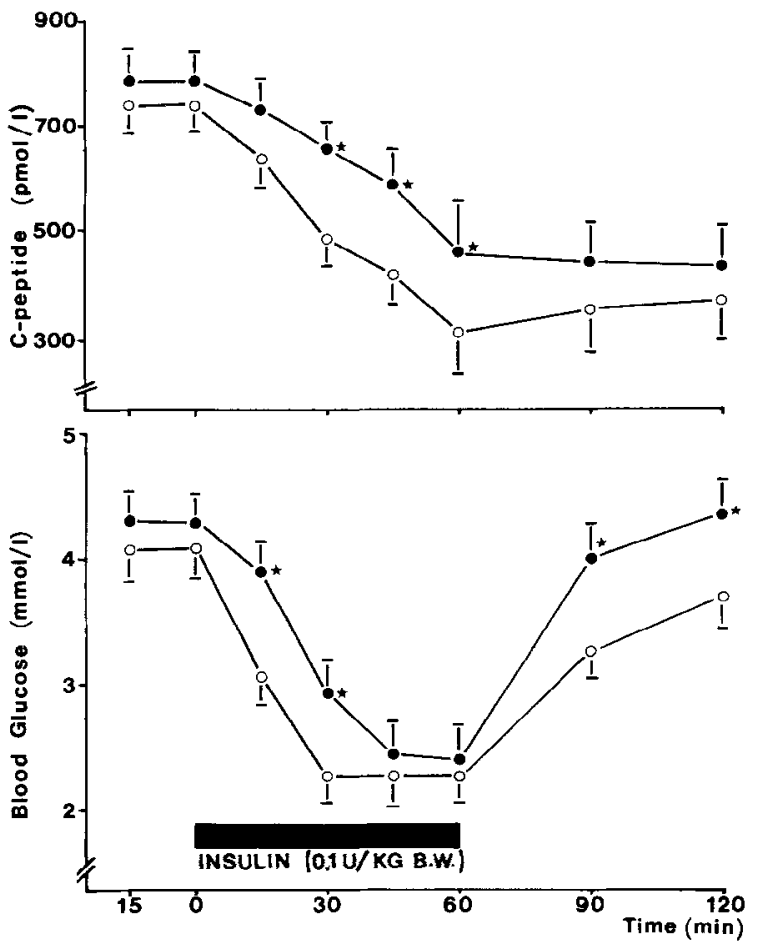

Fig. 2. Immunoreactive C-peptide and blood glucose levels during intravenous insulin tolerance test in hyperprolactinaemic patients and controls. $\longrightarrow$ hyperprolactinaemic patients $(n=10) ; 0-0$ control subjects $(n=20) ;{ }^{*} p<0.01$

(dispotassium salt). Mononuclear leucocytes were isolated by gradient centrifugation [13]. After centrifugation and cell separation ${ }^{125} \mathbf{J}$ A14 insulin binding to monocytes (sp. act. $250 \mu \mathrm{Ci} / \mu \mathrm{g}$, Novo Research Institute, Copenhagen, Denmark) was studied, using the method of Beck-Nielsen et al. [14]. The details of the test procedure used in our laboratory have been described previously [15]. Monocytes were identified by $\alpha$-naphtyl-acetyl-esterase staining [16] and the specific cell-binding fraction was adjusted to a standard concentration of monocytes of $1.0 \times 10^{7}$ cells $/ \mathrm{ml}$. No statistically significant difference was observed between the numbers of monocytes in hyperprolactinaemic patients and control subjects. Non-specific binding of the monocyte assay was $5.1 \% \pm 2.9 \%$. Insulin binding to erythrocytes was determined, using the method originally described in detail by Pedersen et al. [17]. Erythrocytes were washed and incubated in Hepes buffer $(100 \mathrm{mmol})$ at $15^{\circ} \mathrm{C}$ for $210 \mathrm{~min}$. The mean volume fraction of erythrocytes was $0.44 \pm 0.04$, there being no statistically significant differences between patients and controls. Duplicates of $500 \mu 1$ cell suspension were incubated with ${ }^{125} \mathrm{~J}$-A 14 -labelled insulin at a final concentration of $34 \mathrm{pmol} / \mathrm{l}$, with and without increasing amounts of native insulin. At the end of the incubation period, cell-bound and free insulin were separated by cell centrifugation. Radioactivity which remained bound in the presence of an excess of native insulin was considered as non-specific binding and averaged $13.2 \% \pm 4.6 \%$ of the total cell-bound fraction. Specific cell binding was defined as total cell binding minus non-specific binding fraction.

\section{Analysis of binding data}

The results of the binding studies are presented as specific cell-bound fraction, plotted as a function of total insulin concentration (competition curve). Binding data were further analysed by Scatchard analysis [18] and by the average affinity model of De Meyts and Roth [19].

\section{Analytical procedures}

To avoid interassay variation, all plasma samples were stored at $-20{ }^{\circ} \mathrm{C}$ until glucose and hormone concentrations had been determined. Plasma glucose levels were measured by the glucose oxidase method and concentrations of immunoreactive insulin, immunoreactive C-peptide, immunoreactive prolactin, oestradiol and DHAS were measured using commercially available radio-immunoassay kits. The Wilcoxon rank test and the Mann-Whitney non-parametric test were used for statistical evaluation where appropriate. The significance of any correlation between variables was determined by calculation of the correlation coefficient( $r$ ) and by least-squares linear regression analysis. The results are presented as mean \pm SEM.

\section{Results}

\section{Oral glucose tolerance and intravenous glucose tolerance test}

After oral glucose load, patients with hyperprolactinaemia showed significantly higher blood glucose levels $(p<0.01$ at $30,90,120$ and $180 \mathrm{~min})$ than the control group (Fig.1 A). Eight patients did not fulfil the criteria of impaired glucose tolerance [11], whereas two patients (nos. 2 and 6) had slightly elevated blood glucose concentrations after $120 \mathrm{~min}(8.0 \mathrm{mmol} / \mathrm{l}$ and $8.2 \mathrm{mmol} / \mathrm{l}$ respectively). Insulin secretion after oral glucose load (Fig. 1A) was elevated (significantly at $30 \mathrm{~min}, p<0.01$ ) in the patients compared with the controls. In the early phase of the intravenous glucose tolerance test, blood glucose and insulin concentrations were significantly higher in patients $(p<0.01$ at 5,10 and $15 \mathrm{~min}$ ) than in the control group (Fig. 1B). Glucose disappearance as estimated by the $k$-value did not significantly differ between the hyperprolactinaemic patients $(1.69 \pm 0.1)$ and the control subjects $(1.87 \pm 0.06)$.

\section{Insulin tolerance test (Fig. 2)}

Infusion of insulin resulted in a significantly more pronounced hypoglycaemic effect in the control subjects compared with the hyperprolactinaemic patients $(p<$ 0.01 at 15, 30, 90 and $120 \mathrm{~min}$ ). Endogenous insulin secretion was inhibited during the infusion of exogenous insulin in both groups, as indicated by the suppression of C-peptide levels. The inhibition of endogenous insulin secretion was somewhat diminished in the hyperprolactinaemic patients compared with the controls $(p<0.01$ at 30,45 and $60 \mathrm{~min})$.

\section{Insulin binding studies (Fig. 3)}

The data on the binding of ${ }^{125} \mathrm{~J}$-insulin to monocytes in hyperprolactinaemic patients and controls are shown in Fig. $3 \mathrm{~A}$. In the presence of $0.1-10 \mathrm{nmol} / \mathrm{l}$ insulin, there was significantly less binding of insulin to the monocytes of patients than to cells from the healthy subjects $(p<0.01)$. However, when exposed to concentrations $>10 \mathrm{nmol} / \mathrm{l}$ of insulin, monocytes from patients did not bind significantly less insulin $(p>0.05)$ than those from normal subjects. Scatchard analysis of the binding data revealed that the main reason for there being less insulin binding to monocytes was a decrease in the number of absolute receptors. There were similar findings regarding insulin binding to erythrocytes (Fig. $3 \mathrm{~B}$ ). In pat- 

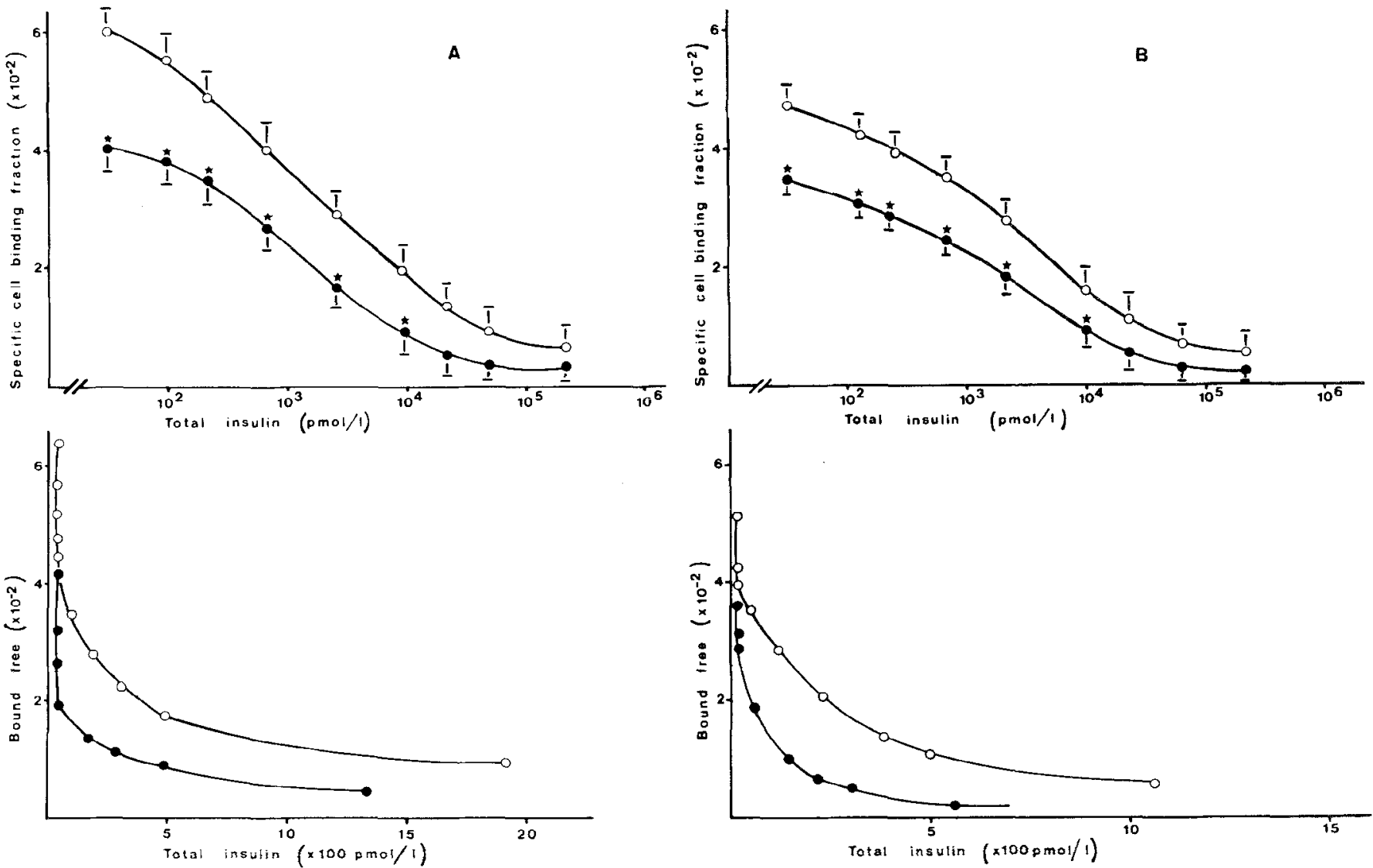

Fig.3. Insulin binding to mononuclear leucocytes (Fig. 3 A) and to erythrocytes (Fig. 3 B) of hypcrprolactinaemic patients and control subjects (upper part). Scatchard plot (lower part); bound to free ratio of ${ }^{125} \mathrm{I}$ insulin $(\mathrm{B} / \mathrm{F})$ is plotted as a function of the insulin bound. The extrapolation of the curve to the horizontal axis is used to derive the total receptor concentration $\left(\mathrm{R}_{0}\right)$. $\longrightarrow$ hyperprolactinaemic patients $(n=10) ; \mathrm{O}-\mathrm{O}$ control subjects $(n=20) ; * p<0.01$

ients with hyperprolactinaemia, insulin binding to erythrocytes was significantly decreased in comparison to controls, merely because of a decrease in the number of erythrocyte receptors. No correlation was found between prolactin levels on the one hand, and insulin binding to monocytes and erythrocytes as well as insulin levels during oral glucose tolerance test and intravenous glucose tolerance test on the other. No correlation was found either between oestradiol or DHAS levels and insulin binding or insulin secretion data.

\section{Discussion}

In the present study carefully selected hyperprolactinaemic patients demonstrated significantly elevated glucose and insulin levels following an oral or intravenous glucose load compared with control subjects. Two patients fulfilled the criteria of impaired glucose tolerance [11]. The underlying mechanism of hyperinsulinaemia in patients with chronic prolactin excess despite normal glucose tolerance or mild glucose intolerance is not readily apparent. Augmentation of $\beta$-cell secretion could be due to a direct $\beta$-cytotropic action of prolactin. However, Landgraf et al. [4] found no evidence for such a relationship in perfusion studies on the isolated rat pancreas. On the other hand, hyperinsulinaemia may be a consequence of increased gluconeogenesis in the liver or enhanced peripheral resistance to insulin. Formal studies of hepatic glucose production would be of interest, but have not yet been performed in patients with long-term endogenous hyperprolactinaemia. Experimental studies in normal dogs given prolactin over several days [2] showed an increase in both glucose production and glucose utilization, whereas plasma insulin and glucose levels remained virtually unchanged. Although the role of the liver in glucose intolerance remains to be investigated, this mechanism does not seem to be the dominating or only one in hyperprolactinaemic patients.

Various experimental and clinical studies suggest that prolactin per se or associated mechanisms may induce some kind of insulin resistance [1-6]. Administration of ovine prolactin has had diabetogenic effects in dogs [2] and has induced insulin resistance in hypophysectomized human diabetics [3]. The hypothesis that severe hyperprolactinaemia is associated with a diminished sensitivity of peripheral tissue to insulin is supported by the present study, which shows that (1) insulin binding at low insulin concentrations is significantly decreased and (2) infusion of exogenous insulin results in a delayed hypoglycaemic effect and a dimin- 
ished inhibition of endogenous insulin secretion. Although we were unable to demonstrate significant correlations between decreased insulin binding and absolute serum prolactin levels, such connections cannot be excluded in a larger group of patients. One of the possible explanations for the lack of correlation could be the existence of circulating immunoreactive prolactin with reduced biological activity. Furthermore, the duration of the excess of prolactin might also be a variable and important factor, but could not be exactly identified in the present or previous studies.

Chronic hyperprolactinaemia presumably suppresses gonadal steroid output and stimulates adrenocortical androgen production [20]. Since gonadal and adrenocortical steroids might regulate the activity of insulin receptors and appear to influence glucose homeostasis via effects on insulin action, possible relationships were analysed. Oestradiol levels were significantly decreased and DHAS concentrations significantly increased, confirming previous findings on hyperprolactinaemic patients [20], but showed no correlation with the data on insulin receptors, the degree of glucose imbalance or the insulin response. A close correlation may have been missed, where not a single hormonal mechanism but a combined effect of prolactin excess and altered steroid concentrations opposed insulin action in peripheral tissues and consequently modified insulin secretion. Recent noteworthy studies [22-24] have questioned whether androgens or gonadal steroids have a strong influence on insulin sensitivity. Shoupe and Lopo [22] did not observe any correlation between hyperinsulinism and DHAS levels in the polycystic ovary syndrome. Moreover, in vivo insulin sensitivity and insulin binding to fat cells [24] have been found to be unchanged during the menstrual cycle, which does not support the hypothesis that progesterone or oestradiol have important effects on in vivo insulin-mediated glucose uptake.

In conclusion, we found that patients with significantly increased prolactin have impaired insulin receptor binding, which may decrease insulin effectiveness in vivo. The existence of in vivo insulin resistance in severe hyperprolactinaemia is supported by the diminished hypoglycaemic effect of insulin infusion and by preliminary findings obtained in hyperglycaemic clamp studies [25] showing diminished peripheral insulin sensitivity.

\section{References}

1. Houssay BA, Penhos JC (1956) Diabetogenic action of pituitary hormones on adrenalectomized hypophysectomized dogs. Endocrinology 59: 637-641

2. Rathgeb IB, Winkler B, Steele R, Altszuler N (1971) Effect of ovine prolactin administration on glucose metabolism and plasma insulin levels in the dog. Endocrinology 88: 718-722

3. BeckJC, Gonda A, Hamid MA, Morgen RO, Rubinstein D, McGarry EE (1964) Some metabolic changes induced by primate growth hormone and purified ovine prolactin. Metabolism 13: 1108-1134
4. Landgraf R, Landgraf-Leurs MMC, Weissmann A, Hörl R, von Werder K, Scriba PC (1977) Prolactin: a diabetogenic hormone. Diabetologia 13: 99-104

5. Gustafson AB, Banasiak MF, Kalkhoff RK, Hagen TC, HakJoong K (1980) Correlation of hyperprolactinaemia with altered plasma insulin and glucagon: similarity to effects of late human pregnancy. J Clin Endocrinol Metab 51: 241-246

6. Johnston DG, Alberti KGMM, Nattrass M, Burrin JM, BlesaMalpica G, Hall K, Hall R (1980) Hyperinsulinaemia in hyperprolactinaemic women. Clin Endocrinol 13:361-368

7. Katz EJ, Donald RA, Beaven DW, Espiner EA (1981) Lack of effect of hyperprolactinaemia on glucose disposal and insulin secretion in patients with prolactinomas. Horm Metab Res 13: 667-669

8. Hagen C, Pedersen PB, Jensen SB, Faber OK, Jensen T (1979) The effect of supiride induced hyperprolactinaemia on glucose tolerance and insulin secretion in normal subjects. Clin Endocrinol 10: $55-60$

9. Harter M, Krebs N, Balarac JM, Kozlowski RM, Chichmaninan S, Strulo S, Carnivet B (1978) Interrelations between prolactin and carbohydrates. In: Robyn C, Harter M (eds) Progress in prolactin, physiology and pathology. Elsevier/North-Holland, Biomedical Press, pp 331-349

10. Adler RA, Sokol HW (1982) Glucose tolerance in rats with elevated circulating prolactin levels. Horm Metab Res 14: 307-309

11. Renauld A, Sverdlik RC, Andrade LL (1973) The effect of chronic prolactin administration upon the blood sugar, insulin and free fatty acid response to a glucose load in the dog. Acta Diabetol Lat 10: 1286-1299

12. WHO Expert Committee on Diabetes mellitus (1980) WHO Tech Rep 646

13. Boyum A (1968) Separation of leukocytes from blood and bone marrow. Scand J Lab Clin Invest 22 (Suppl 97): 77-89

14. Beck Nielsen H, Pedersen O, Kragballe K, Sörensen NS (1977) The monocytes as a model for the study of insulin receptors in men. Diabetologia 13: 563-569

15. Prager R, SchernthanerG (1983) Insulin receptor binding to monocytes, insulin secretion and glucose tolerance following metformin treatment, results of a double blind cross-over study in type II diabetics. Diabetes 32: 1083-1086

16. Yam LT, Li CY, Crosby WN (1971) Cytochemical identification of monocytes and granulocytes. Am J Clin Pathol 55: 283-286

17. Pedersen O, Beck Nielsen H, Heding L (1980) Increased insulin receptors after exercise in patients with insulin dependent diabetes mellitus. New Engl J Med 302: 886-892

18. Scatchard $G$ (1949) The attraction proteins for small molecules and ions. Ann NY Acad Sci 51: 660-672

19. DeMeyts $P$, Roth $J$ (1975) Cooperativity in ligand binding: A new graphic analysis. Biochem Biophys Res Commun 66: 1118-1126

20. Carter JN, Tyson JE, Warne GL, McNeilly AS, Faiman C, Friesen HG (1977) Adrenocortical function in hyperprolactinemic women. J Clin Endocrinol Metab 45: 973-980

21. Lenzen S, Bailey CJ (1984) Thyroid hormones, gonadal and adrenocortical steroids and the function of the islets of Langerhans. Endocr Rev 5: 411-434

22. Shoupe D, Lobo RA (1984) The influence of androgens on insulin resistance. Fertil Steril 41:385-388

23. Yki-Järvinen H (1984) Insulin sensitivity during the menstrual cycle. J Clin Endocrinol Metab 59: 350-353

24. Pedersen O, Hjollund E, Lindskov HO (1982) Insulin binding and action on fat cells from young healthy females and males. Am J Physiol 243: E158

25. Luger A, Graf H, Prager R, Schernthaner G (1984) Decreased peripheral insulin sensitivity in hyperprolactinemic patients. Acta Endocrinol (Copenh) 105 (Suppl 364): 44

Dr. G. Schernthaner

Department of Medicine II

Division of Metabolism and Endocrinology

University of Vienna

Garnisongasse 13

A-1090 Vienna

Austria 